patients, and in these the risk of imbalance is much greater.

How should imbalance be dealt with? The crucial question is whether the variable in question is related to the outcome being studied. If, for example, one treatment group is on average five years older than the other this will be of varying importance for outcomes such as survival time, reduction in blood pressure, or response to treatment for eczema. In the first instance both clinical knowledge and simple statistical analysis may be used to identify potentially important imbalances, and various statistical approaches can be used to investigate further. A more advanced statistical analysis, using modelling techniques, may be needed, in which case, as Lavori et al suggest, expert statistical help is recommended. ${ }^{2}$ Only one of the 47 trials they reviewed had adopted this approach; they thought that over half could have benefited in this way. If there is a strongly prognostic variable there are good grounds for using the modelling approach even when perfect balance is achieved. ${ }^{26}$

In many cases some variables of prognostic importance can be identified when a clinical trial is being planned. Various techniques exist for ensuring balance between groups for important variables, the best known being stratified randomisation. ${ }^{27}$ Such methods may be especially beneficial in small trials or where a particular variable is known to have a powerful influence on outcome.

Statistician,

Douglas G Altman

Clinical Research Centre,

Harrow, Middlesex HAl $3 \mathrm{UJ}$

1 Rothman K. Epidemiologic methods in clinical trials. Cancer 1977;39:1771-5.

2 Lavori PW, Louis TA, Bailar JC III, Polansky M. Designs for experiments- parallel comparisons of treatment. N Engl f Med 1983;309:1291-9.

Flaherty JT, Becker LC, Bulkley BH, et al. A randomised prospective trial of intravenous nitroglycerin in patients with acute myocardial infarction. Circulation 1983;68:576-88.

Holman RR, Steemson J, Darling P, Reeves WG, Turner RC. Human ultralente insulin. Br Med $\mathcal{f}$ 1984;288:665-8.

Halliday HL, McClure G, Reid MMcC, Lappin TRJ, Meban C, Thomas PS. Controlled trial of artificial surfactant to prevent respiratory distress syndrome. Lancet $1984 ; \mathrm{i}: 476-8$

Clinical $P$. Importance of prognostic factors in the analysis of data from clinical trials. Controlled

7 Pocock SJ. Clinical trials. A practical approach. Chichester: Wiley, 1983.

\section{Ultrasound brain scanning in the newborn}

Tired of reassuring mothers that the soft spot on top of baby's head is harmless and will close, neonatologists are now exploiting it as the window to the brain. Good quality coronal and sagittal images of the brain may be obtained using a real time ultrasound probe positioned over the anterior fontanelle. ${ }^{\prime}$ Both periventricular haemorrhage and cystic degeneration within haemorrhagic or infarcted areas may be diagnosed reliably and ventricular size accurately measured. ${ }^{23}$

Research studies using daily imaging have shown that 40$50 \%$ of preterm babies who weigh less than $1500 \mathrm{~g}$ suffer periventricular haemorrhage in the first three days of life. ${ }^{45}$ The haemorrhage (often silent) originates in the subependymal region; it may be confined here or it may extend by varying degrees into the ventricular system. A few infants suffer large haemorrhages with intracerebral extension. Some ventricular dilatation, presumably associated with obstruction to the flow of cerebrospinal fluid, is seen in 30 $50 \%$ of babies with periventricular haemorrhage. ${ }^{6}$ Between $10 \%$ and $20 \%$ of these babies develop progressive enlargement of the ventricles and enlargement of the head requiring a cerebrospinal fluid shunt procedure.
Daily scanning has also identified the clinical antecedents of periventricular haemorrhage in preterm babies-notably respiratory distress syndrome, hypoxaemia, hypercapnoea, acidaemia, mechanical ventilation, and pneumothoraces. ${ }^{57}$ Perhaps its most important research application is in evaluating preventive measures against periventricular haemorrhage, such as phenobarbitone,${ }^{8}$ ethamsylate, ${ }^{9}$ and vitamin E. ${ }^{10}$

Should ultrasound imaging of the brain now be introduced for routine use in special care baby units? The dynamic nature of periventricular haemorrhage and ventricular dilatation limits the value of a single scan performed during the first week of life. Daily scanning requires not only a portable scanner to examine ill babies by the cot side but a dedicated and experienced ultrasonographer. No specific treatment is available for periventricular haemorrhage so that the diagnosis by ultrasound of a silent periventricular haemorrhage cannot really influence a baby's care. When there are non-specific signs consistent with periventricular haemorrhage-such as recurrent apnoea, seizures, or circulatory failure-confirmation by ultrasound of periventricular haemorrhage should not deter the vigilant neonatologist from seeking a treatable coexisting disorder such as sepsis or hypoglycaemia which might itself be responsible for the baby's deterioration. Whether early recognition of progressive ventricular dilatation and treatment by repeated lumbar puncture reduce the incidence of clinical hydrocephalus or neurological sequelae is uncertain -and is currently the subject of a randomised multicentre trial (convenor, A Whitelaw, Hammersmith Hospital, London).

When brain scanning was first introduced there were hopes that it would help to resolve the ethical dilemma of whether to withdraw ventilatory support from critically ill, neurologically unresponsive babies with clinical evidence of hypoxic-ischaemic or haemorrhagic encephalopathy. The initial optimism must now be tempered with caution. Most parents prefer such babies to die a dignified death in their arms rather than in an incubator s trrounded by the trappings of intensive care; it would be a pity if that humane approach was precluded when the brain scan failed to show gross abnormalities. Paediatricians who argue that the reward of having a more complete picture of their patients' condition is itself justification for daily brain scanning must be warned that a price has to be paid for routinely "looking" at babies' brains. Firstly, unless nursing and medical staff are properly counselled, the confident, positive, and optimistic ambience of the special care baby unit might be replaced by endemic despondency with whispers of "brain damage." Secondly, what should parents be told when, for example, a small, silent periventricular haemorrhage is observed by routine scanning? No matter how the doctor may try to convey the good prognosis there is no euphemism for brain haemorrhage. "Just a little leak of blood" or "a tiny vessel has leaked" might do if it were some other part of the baby's body-but not his brain.

Recently, Stewart and her colleagues at University College Hospital, London, have defined the probability of neurodevelopmental disorders in preterm babies at 18 months based on the neonatal brain scan findings. ${ }^{11} \mathrm{~A}$ group with a low risk (8\%) for such disorders was clearly distinguished from a group with a high risk (83\%). A single scan performed when a preterm baby is discharged from the special care baby unit might prove to be the most cost effective use of ultrasound brain imaging.

Finally, and most important, knowledge derived from the 
use of scanning in research ${ }^{57}$ and information from other non-invasive measurements such as cerebral blood flow velocity have suggested that periventricular haemorrhage may be prevented by the employment of a sufficient number of skilled nurses and doctors to provide high quality care for ill preterm babies. ${ }^{12-14}$ Our resources must be directed there rather than to the detection of periventricular haemorrhage after it has occurred.

\section{Malcolm L Chiswick}

Consultant Paediatrician,

North Western Regional Perinatal Centre,

St Mary's Hospital,

Manchester M12 0JH

1 Gowland M, Chiswick ML. Ultrasound imaging of the brain in the newborn. In: Chiswick ML ed. Recent advances in perinatal medicine. Vol I. Edinburgh: Churchill Livingstone, 1983:

2 Pape KE, Blackwell RJ, Cusick G, et al. Ultrasound detection of brain damage in preterm infants Lancet 1979; i: $1261-4$.

Levene MI. Measurement of the growth of the lateral ventricles in preterm infants with real time ultrasound. Arch Dis Child 1981;56:900-4

Levene MI, Wigglesworth JS, Dubowitz V. Cerebral structure and intraventricular haemorrhage in the neonate: a real-time ultrasound study. Arch Dis Child 1981;56:416-24

Thorburn RJ, Lipscomb AP, Stewart AL, et al. Timing and antecedents of periventricula haemor $221-38$.

6 Levene MI, Starte DR. A longitudinal study of post-haemorrhagic ventricular dilatation in the newborn. Arch Dis Child 1981:56:905-10

Tymonowicz W, Yu VYH, Wilson FE. Antecedents of periventricular haemorrhage in infants weighing $1250 \mathrm{~g}$ or less at birth. Arch Dis Child 1984;59:13-7.

Donn SM, Roloff DW, Goldstein GW. Prevention of intraventricular haemorrhage in preterm infants by phenobarbitone. Lancet 1981;ii:215-7.

Morgan MEI, Benson JWT, Cooke RWI. Ethamsylate reduces the incidence of periventricula haemorrhages in very low birthweight babies. Lancet 1981 ;ii:830-1.

10 Chiswick ML, Johnson M, Woodhall C, et al. Protective effect of vitamin E DL-alphatocopherol) against intraventricular haemorrhage in preterm babies. Br Med f 1983;287:81-4 Stewart AL, Hope PL, Costello AM de L, et al. Ultrasound appearance of the brain in ver preterm infants and probability of neurodevelopmental disorders at 18 month

2 Perlman JM McMenamin JB Volpe JJ. Fluctuating cerebral blond-flow velocity in respiratory distress svndrome. Relation to the development of intraventricular hemorrhage. $N$ Engl 7 Med 1983;309:204-9.

13 Perlman JM, Volpe JJ. Seizures in the preterm infant: effects on cerebral blood flow velocity, intracranial pressure, and arterial blood pressure. F Pediatr 1983;102:288-93.

14 Perlman JM, Volpe JJ. Suctioning in the preterm infant: effects on cerebral blood flow velocity. intracranial pressure, and arterial blood pressure. Pediatncs 1983;72:329-34

\section{The 80th year of fifth disease}

Recently fifth disease has been attributed to the human parvovirus, B19,' so uniting an illness defined 80 years ago with an orphan virus recognised in 1975 .

Fifth disease, or erythema infectiosum, is a minor, acute infection characterised by malar erythema ("slapped cheeks"), a secondary rash mainly on the limbs, and a mild constitutional upset. ${ }^{+}$Typically both cheeks are covered by a raised, fiery flush, which often extends across the bridge of the nose but spares the area around the mouth. The secondary rash is seen a day or so later; it is variable, blotchy or spotty at first, then fading to a lacy pattern that becomes more prominent when the skin is irritated by heat or pressure. Cases are often recognised in schools and other institutions, and large community outbreaks have been described."

In sporadic cases fifth disease may be impossible to distinguish from other childhood rashes, such as that of rubella, but in outbreaks it may be easily recognised because of the frequent presentation with scarlet cheeks. Fifth disease has the typical features of an epidemic viral infection. It is seasonal, mainly affects children in their early school years, and spreads rapidly in closed communities. It usually occurs a little later in childhood than measles and chickenpox, which suggests that it is rather less infectious. Like rubella, it is readily transmitted to adults, often giving rise to joint pains-the most common complaint of adults who acquire the disease.

Until recently no virus had been consistently associated with fifth disease, but since specific serological tests have been applied to stored sera outbreaks have been retrospectively ascribed to the human parvovirus. Confirmation that the human parvovirus causes the disease is emerging from the investigation of several outbreaks that occurred in Britain last winter.

The human parvovirus was found independently by three groups, in Britain, ${ }^{3}$ France, ${ }^{8}$ and Japan." In all three instances it presented as a particulate antigen in the serum of blood donors, most of whom were asymptomatic. The particle mimics the surface antigen of hepatitis B virus ( $\mathrm{HBsAg}$ ) and has probably been seen without its significance being recognised in other laboratories screening large numbers of sera for HBsAg. More specific tests showed that the particle was different from HBsAg, and electron microscopy disclosed that it had the size and structure of a parvovirus. This tentative identification has now been confirmed by biochemical analyses. ${ }^{1011}$ The parvoviruses form a family of small spherical viruses, some of which are dependent on another virus for their replication while others are autonomous and can cause severe acute infections in their host species. ${ }^{12}$ Both in nature and in the laboratory they replicate best in rapidly dividing cells. Specific parvovirus infections of various animals cause an enteritis and a profound leucopenia, and disrupt differentiating fetal tissue. Similar effects might have been expected in human parvovirus infection, but none have been apparent. Isolated reports appeared in the 1970s of fever, abdominal and joint pains, and evanescent rashes, but no clinical pattern was discerned, and most instances of parvovirus viraemia were seen in asymptomatic individuals. Nevertheless, about a third of older children and adults were known to have antibody to the virus even by an insensitive test, ${ }^{2}$ and it seemed unlikely that so common an infection would lack any characteristic clinical expression.

While using a seroepidemiological approach to look for a clinical effect Pattison and his colleagues discovered that the human parvovirus was a cause of aplastic crisis in sickle cell disease. ${ }^{1314}$ These crises occur, and have since been associated with human parvovirus infection, in all forms of inherited haemolytic anaemia.

Indeed, the parvovirus may be their sole cause. Aplastic crises are due to a transient arrest of erythropoiesis, and a similar arrest of the activity of the bone marrow characterises infections by the feline and canine parvoviruses, leading to a panleucopenia and a hypoplastic anaemia. Apparently all three parvoviruses have target cells in the bone marrow. Sera containing the human parvovirus inhibit the growth of the red cell lineage colonies in cultures of bone marrow cells, and this effect may be neutralised by convalescent serum. ${ }^{15}$ The same interruption of erythropoiesis presumably occurs in vivo, not only in patients with haemolytic anaemia but also in normal people. The latter, however, are protected from the results of the ensuing red cell deficit by their peripheral cell reserve.

The clinical effects of the virus in healthy individuals remained uncertain. Various acute conditions of unknown aetiology were investigated, and the non-haematological features of aplastic crises were analysed, but no clues were found. Then the new evidence emerged. Immunoglobulin $M$ antibody to human parvovirus was found in sera from British and foreign outbreaks of fifth disease dating back to 1962 (PHLS Communicable Disease Report 1984/07, unpublished), suggesting that the disease was a common clinical manifestation of human parvovirus infection and also that the virus was a common cause of the disease. The 